\title{
Radiative Auger Effect and Extended X-Ray Emission Fine Structure (EXEFS)
}

\author{
Jun KaWAI \\ Department of Materials Science and Engineering, Kyoto University, Sakyo-ku, Kyoto 606-8501, Japan
}

\begin{abstract}
Radiative Auger spectra are weak X-ray emission spectra near the characteristic X-ray lines. Radiative Auger process is an intrinsic energy-loss process in an atom when a characteristic X-ray photon is emitted, due to an atomic many-body effect. The energy loss spectra correspond to the unoccupied conduction band structure of materials. Therefore the radiative Auger effect is an alternative tool to the X-ray absorption spectroscopy such as EXAFS (Extended X-ray Absorption Fine Structure) and XANES (X-ray Absorption Near Edge Structure), and thus it is named EXEFS (Extended $\mathrm{X}$-ray Emission Fine Structure). By the use of a commercially available X-ray fluorescence spectrometer or an electron probe microanalyzer (EPMA), which are frequently used in materials industries, we can obtain an EXEFS spectrum within $20 \mathrm{~min}$. The radiative Auger effect, as an example, demonstrates that the study on atomic many-body effects has become a powerful tool for crystal and electronic structure characterizations. The EXEFS method has already been used in many industries in Japan. Reviews about the applications and basic study results on the radiative Auger effect are reported in this paper.
\end{abstract}

(Received December 23, 2004; Accepted March 10, 2005)

\begin{tabular}{llll}
\hline 1 Introduction & 733 & 3 Progress of EXEFS Method & 734 \\
2 EXEFS & 734 & 4 References & 735 \\
& & & \\
\hline
\end{tabular}

\section{Introduction}

The radiative Auger satellite spectra are observable at the low energy side of stronger characteristic X-ray emission lines, such as $K_{\alpha}$ and $K_{\beta}$. The radiative Auger effect is a shake-up process at the moment of electric dipole transition of an electron from an outer shell to an inner shell. The shake-up process is an electron excitation process due to the sudden change of atomic potential. The atomic potential is suddenly changed when an inner electron is photoionized, an inner electron is ionized by an atomic collision, or an electron is moved from an outer shell to an inner shell. Any kind of sudden change of atomic potential cause another outer shell electron to excite into a discrete unoccupied state or the continuum state. If an electron is excited into a discrete level, it is called shake-up; an electron is ionized into a continuum level, it is called shake-off. The probability that an electron in an orbital $\phi$ before the sudden change of the potential remains in the same orbital $\phi^{*}$ is expressed by the overlap integral $\left|\left\langle\phi \mid \phi^{*}\right\rangle\right|^{2}$, where the asterisk denotes the slight change of orbital wavefunction due to the change of the atomic potential.

The shake-up satellites are remarkable in X-ray photoelectron spectra of molecules, where discrete weak lines are observable. The shake-off spectra in the X-ray photoelectron spectra are continuum spectra. These shake-up and shake-off satellite structures in X-ray photoelectron spectra are due to the sudden change at photoionization. Another example of shake-off spectra are the $K_{\alpha_{3,4}}$ satellite lines of X-ray fluorescence spectra. The $K_{\alpha_{3,4}}$ satellites are due to the $2 \mathrm{p}$ electron shake-off at the moment of $1 \mathrm{~s}$ electron photoionization.

The potential energy function of an atom whose 1s electron is absent due to photoionization is different from that of the same atom but one of the $2 p$ electrons is absent. An outer electron feels this difference before and after the $K_{\alpha} \mathrm{X}$-ray emission (2p $\rightarrow 1 \mathrm{~s})$. Thus the sudden change of an atomic potential before and after the X-ray emission causes another electron ionization or excitation due to the shake-off or shake-up process. This is the radiative Auger effect. ${ }^{1-9}$ The shake process is a monopole transition process, that is to say, the $3 p$ electron is excited into an $n \mathrm{p}$ discrete level or an $\varepsilon \mathrm{p}$ continuum level.

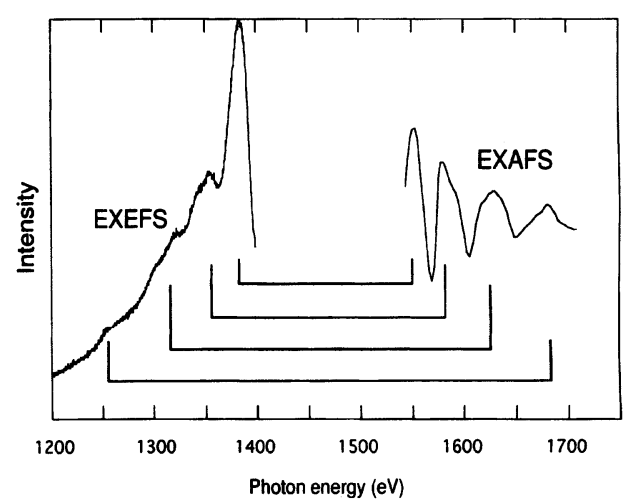

Fig. 1 Comparison of true EXAFS and EXEFS for Al metal, taken from Ref. 24. 


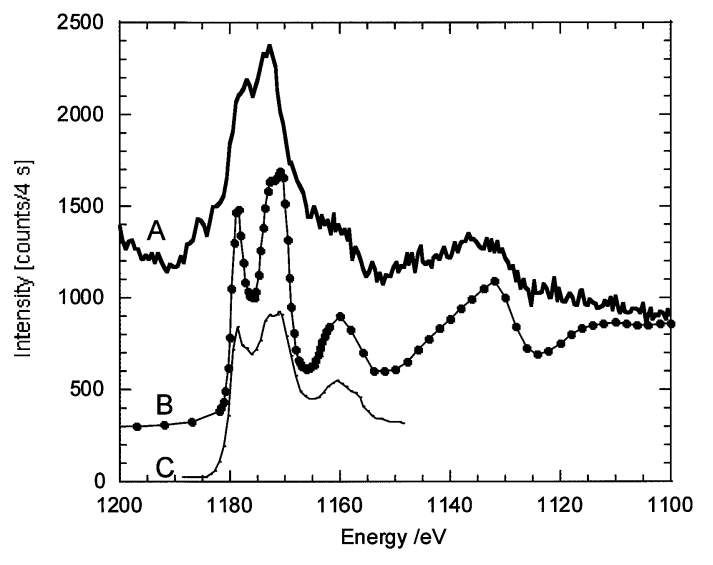

Fig. 2 Comparison of true XANES (B: KEK-PF, C: UVSOR) and EXEFS (A) for $\mathrm{Mg}$ in $\mathrm{MgO}$, taken from Ref. 15.

\section{EXEFS}

Kawai et al. ${ }^{10-12}$ suggested the similarity between the radiative Auger spectra and the X-ray absorption fine structure (XAFS). This was demonstrated for various low atomic number elements, such as $\mathrm{Na},{ }^{13} \mathrm{Mg},{ }^{14-16} \mathrm{Al},{ }^{11,12,17,18}$ and $\mathrm{Si}^{19-23}$ A typical example of the similarity between the radiative Auger spectra and extended X-ray absorption fine structure (EXAFS) is shown in Fig. 1,24 where aluminum metal spectra are compared. The EXAFS is the term for X-ray absorption spectra $50-1000 \mathrm{eV}$ above the threshold energy. The Fourier transform of the oscillating fine structure in EXAFS yields a radial distribution function of the atom in the condensed phase. This characteristic is used to analyze the structure of amorphous, liquid and crystalline materials.

The X-ray absorption near edge structures (XANES) in X-ray absorption spectra are the term for the fine structure up to $50 \mathrm{eV}$ above the threshold energy. The XANES spectral shape has a close relation to the unoccupied local and partial density of states of the X-ray absorbing atom. An example of XANES and the radiative Auger spectra is shown in Fig. 2,15 where the spectra of $\mathrm{Mg}$ in an $\mathrm{MgO}$ ionic crystal compound are shown.

Because of the similarity between XAFS and the radiative Auger spectra, Kawai et al. ${ }^{18}$ coined EXEFS (extended X-ray emission fine structure) for the radiative Auger satellites, where XAFS (X-ray absorption fine structure) is the generic name for the XANES and EXAFS. The similarity of EXEFS and XAFS has recently been theoretically proved. ${ }^{25,26}$

\section{Progress of EXEFS Method}

The EXEFS method started in Japan, and many of the review papers are written in Japanese, ${ }^{24,27-29}$ as well as English. ${ }^{30-33}$

Three PhD theses were published on the EXEFS method on the application of EXEFS method. ${ }^{34-36}$ Takahashi et al. ${ }^{37}$ reported an application of EXEFS to chemical state analysis with using an electron probe microanalyzer. Watanabe et al. ${ }^{38}$ reported that, with the use of EXEFS, aluminum compounds, which were difficult to discriminate from each other by the elemental analysis, could be analyzed with a high spatial resolution (Fig. 3). Taguchi ${ }^{39}$ wrote and installed the EXEFS Fourier transform program (EXEFS Analysis Software) into commercial X-ray fluorescence spectrometer for elemental

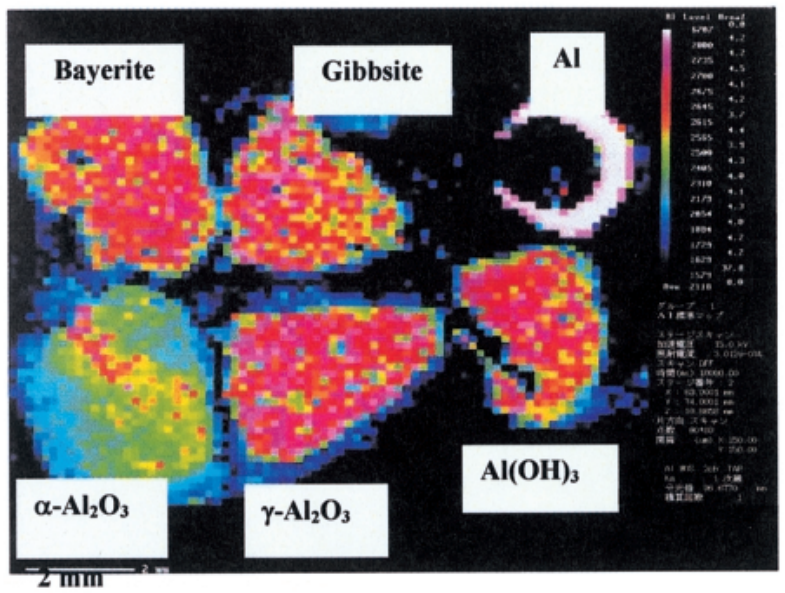

Fig. 3 Mapping of chemical states of aluminum, taken from Ref. 38.

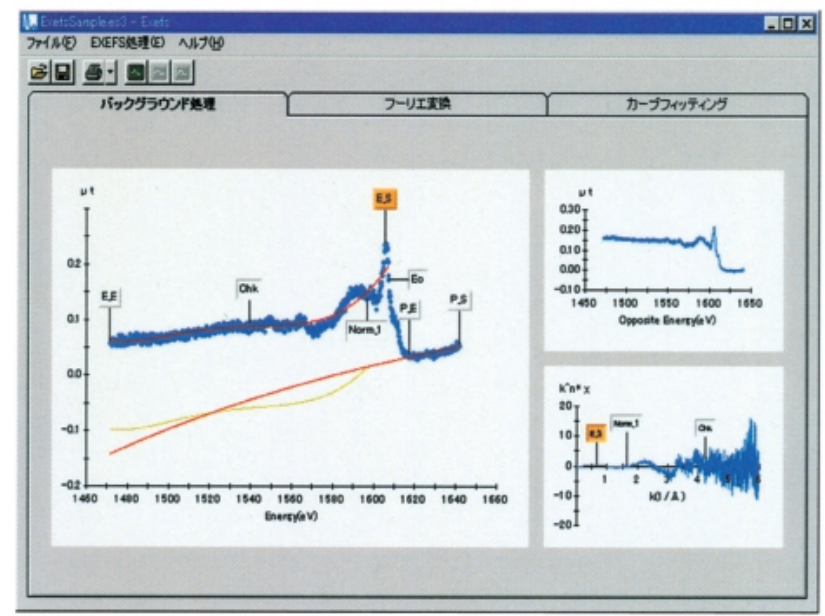

Fig. 4 CRT display view of EXEFS Analysis Software, taken from Ref. 39.

analysis (Fig. 4). Morii et al. studied a metal/silicon contact using the EXEFS method. ${ }^{40}$ Applications of EXEFS to semiconductor wafer $^{41}$ and to environmental analysis ${ }^{42}$ were reported.

Abrahams et al. ${ }^{43}$ have clarified the assignment of multiplet structure in the radiative Auger spectra, and have compared silicon, phosphorus and sulfur (as silica, phosphate and sulfate) radiative Auger spectra with the corresponding real Auger spectra. ${ }^{44}$

$\mathrm{Kawai}^{45}$ recently pointed out the similarity between the "coherent crystal radiation" $46-48$ and the EXEFS spectra.

Atomic number dependence of the EXEFS intensity ${ }^{49}$ and interference with the trace analysis were pointed out by Maeda et al. ${ }^{50}$ Weak lines like EXEFS are still not well understood. ${ }^{51,52}$ The present author strongly believes that the advancement of basic atomic physics will contribute to the chemical state analysis of advanced materials, semiconductor analysis, and environmental analysis, using these weak X-ray satellite lines as an index for the chemical state of the X-ray emitting atom.

This work was financially supported by a Grant-in-Aid for Scientific Research \#13555232 from the Ministry of Education, Science, and Culture, Japan. 


\section{References}

1. T. Åberg, Phys. Rev., 1971, A4, 1735.

2. T. Åberg and J. Utriainen, J. de Phys. (Paris) Colloq., 1971, 32, C4-295.

3. M. Budnar, A. Mühleisen, M. Hribar, H. Janzekovic, M. Ravnikar, Z. Smit, and M. Zitnik, Nucl. Instrum. Methods Phys. Res., 1992, B63, 377.

4. A. Mühleisen, M. Budnar, and J.-C. Dousse, Phys. Rev., 1996, A54, 3852.

5. C. Herren and J.-C. Dousse, Phys. Rev., 1996, A53, 717.

6. C. Herren and J.-C. Dousse, Phys. Rev., 1997, A56, 2750.

7. M. Kavcic, M. Budnar, A. Mühleisen, and I. Török, Nucl. Instrum. Methods Phys. Res., 1998, B137, 173.

8. A. Mühleisen, M. Budnar, J.-C. Dousse, J. Hoszowska, and Z. G. Zhao, X-Ray Spectrom., 1998, 27, 337.

9. O. Mauron, J.-C. Dousse, J. Hoszowska, J. P. Marques, F. Parente, and M. Polasik, Phys. Rev., 2000, A62, 062508.

10. J. Kawai, T. Nakajima, T. Inoue, H. Adachi, M. Yamaguchi, K. Maeda, and S. Yabuki, Analyst, 1994, 119, 601.

11. J. Kawai, K. Hayashi, and Y. Awakura, J. Phys. Soc. Jpn., 1997, 66, 3337.

12. K. Hayashi, J. Kawai, and Y. Awakura, Spectrochim. Acta, 1997, B52, 2169.

13. J. Kawai, K. Hayashi, and S. Tanuma, Analyst, 1998, 123 , 617.

14. J. Kawai, H. Takahashi, K. Hayashi, S. Okazaki, and Y. Awakura, Tetsu-to-Hagané, 1999, 85, 80.

15. J. Kawai and H. Takahashi, Bunseki Kagaku, 1999, 48, 793.

16. J. Kawai, K. Hayashi, H. Takahashi, and Y. Kitajima, J. Synchrotron Radiat., 1999, 6, 356.

17. S. Tanuma and M. Nishio, Spectrochim. Acta, 1998, B53, 505 .

18. J. Kawai and K. Hayashi, J. Electron Spectrosc. Relat. Phenom., 1998, 92, 243.

19. J. Kawai, K. Hayashi, K. Okuda, and A. Nisawa, Chem. Lett., 1998, 245.

20. J. Kawai, K. Hayashi, K. Okuda, and A. Nisawa, RigakuDenki Journal, 1998, 29(1), 23.

21. J. Kawai, K. Hayashi, K. Okuda, and A. Nisawa, Rigaku Journal, 1998, 15(2), 33.

22. J. Kawai, H. Takahashi, and R. Shimizu, J. Trace Microprobe Tech., 1999, 17, 39.

23. J. Kawai and H. Takahashi, Spectrochim. Acta, 1999, B54, 231.

24. J. Kawai and K. Hayashi, Tetsu-to-Hagané, 1999, 85, 353.

25. J. Kawai J. Electron Spectrosc. Relat. Phenom., 1999, 101 $-103,847$.

26. T. Fujikawa and J. Kawai, J. Phys. Soc. Jpn., 1999, 68 ,
4032.

27. J. Kawai, J. Spectrosc. Soc. Jpn., 1998, 47, 161.

28. J. Kawai, Bunseki, 1999, 387.

29. J. Kawai, Bull. Iron Steel Institute Jpn., 2000, 5, 298

30. J. Kawai, J. Anal. At. Spectrom., 1999, 14, 455.

31. J. Kawai, K. Hayashi, and K. Maeda, Adv. X-Ray Anal., 2000, 42,83 .

32. J. Kawai, "Extended X-ray emission fine structure (EXEFS) of EPMA", in "Microbeam Analysis 2000", 2000, Institute of Physics Conference Series Number 165, Bristol, 463.

33. J. Kawai, "Absorption Techniques in X-ray Spectrometry", in "Encyclopedia of Analytical Chemistry", ed. R. A. Meyers, 2000, Wiley, Chichester, 13288 - 13315.

34. H. Takahashi, PhD Thesis, Osaka University, 1998.

35. T. Watanabe, PhD Thesis, Kobe University, 2000.

36. T. Morii, PhD Thesis, Okayama University, 2002.

37. H. Takahashi, I. Harrowfield, C. MacRae, N. Wilson, and K. Tsutsumi, Surf. Interface Anal., 2001, 31, 118.

38. T. Watanabe, A. Kawano, K. Ueda, N. Umesaki, and H. Wakita, J. Synchrotron Rad., 2001, 8, 334.

39. T. Taguchi, Adv. X-Ray Chem. Anal., Jpn., 2002, 33, 299.

40. T. Morii, H. Watanabe, M. Hirai, M. Kusaka, and M. Iwami, Mater. Sci. Eng., 2002, B96, 150.

41. J. Kawai and H. Takahashi, Surf. Interface Anal., 2001, 31, 114.

42. J. Kawai and S. Tohno, J. Trace Microprobe Tech., 2001, 19, 497

43. I. Abrahams, D. S. Urch, B. Vrebos, and M. West, J. Phys. B-Atom. Mol. Opt. Phys., 1999, 32, L579.

44. I. Abrahams, L. Kover, J. Toth, D. S. Urch, B. Vrebos, and M. West, J. Electron Spectrosc. Relat. Phenom., 2001, 114, 925 .

45. J. Kawai, J. Crystallogr. Soc. Jpn., 2001, 43, 185.

46. K. Das Gupta and H. Welch, Phys. Rev. Lett., 1968, 21 , 657.

47. M. Shah and K. Das Gupta, Phys. Lett., 1969, 29A, 570.

48. K. Onoe and T. Suzuki, Jpn. J. Appl. Phys., 1978, 17(Suppl. 17-2), 439.

49. K. Maeda and J. Kawai, RIKEN Accel. Prog. Rep., 1992, 26,130

50. K. Maeda and J. Kawai, Adv. X-Ray Chem. Anal. Jpn., 1994, 25, 25

51. I. Török, T. Papp, J. Pálinkás, M. Budnar, A. Mühleisen, J. Kawai, and J. L. Campbell, Nucl. Instrum. Methods Phys. Res., 1996, B114, 9.

52. I. Török, J. Pálinkás, M. Budnar, M. Kavcic, A. Mühleisen, and J. Kawai, "Forgotten (?) X-ray intensity enhancement in solids at lines related to not completely filled shells", in "Application of Accelerators in Research and Industry", ed. J. L. Duggan and I. L. Morgan, Conf. Proc No. 392, 1997, AIP Press, New York 153 - 155 